\title{
Diabetes and Rheumatology
}

\author{
Alaa Monjed
}

\subsection{Introduction}

Diabetes mellitus (DM) is a chronic disease characterized by persistent hyperglycaemia that happens as a result of a pancreatic insulin deficiency and/or insulin resistance. Its morbidity and mortality are primarily related to the resultant microvascular and macrovascular complications. Its prevalence has grown widely, which will result in higher rates of diabetic complications including rheumatic manifestations.

An improved understanding of the mechanisms through which diabetes alters connective tissue metabolism should lead to better preventive and therapeutic interventions. In this chapter, a brief summary about the pathophysiology of rheumatological manifestations in diabetes is outlined. A schematic classification of rheumatological manifestations in diabetic patients is demonstrated according to the region and according to the presence or absence of pain. This is followed by summarized review of these rheumatological manifestations of diabetes mellitus. It is obvious that these are not unique to diabetes mellitus as it may affect normal individuals, as well.

\footnotetext{
A. Monjed $(\bowtie)$

College of Medicine, Umm Al-Qura University, Makkah, Saudi Arabia

e-mail: akrmonjed@uqu.edu.sa
}

\subsubsection{Objectives}

The reader of this chapter should be able to:

1. Identify different diabetes related rheumatic complications.

2. Differentiate between rheumatic complications related to diabetes and those associated with other diseases.

3. Classify these rheumatic diseases based on the involved region and the underlying pathophysiology.

4. Assess diabetic patients with rheumatic complications clinically and select the appropriate diagnostic tests.

5. Manage diabetic patients with rheumatic complications.

\subsection{Pathophysiology}

The high glucose, high insulin milieu of diabetes affects many of the key cells and matrix components of connective tissues. For example, reactive oxygen species are increased in diabetes and certainly may mediate tissue damage [1]. Advanced glycosylation end products (AGEs) tend to accumulate in the long-lived proteins of connective tissues and may alter both extracellular matrix structure and function as well as cell viability [2]. Early glycosylation of skin collagen can be decreased by improving glycaemic 
control $[3,4]$. However, the long-term, cumulative damage due to the binding of advanced glycosylation end products to collagen is probably irreversible.

\subsubsection{Classification of Rheumatological Manifestations in Diabetic Patients}

Rheumatological diseases associated with diabetes mellitus can be classified according to:

1. The involved musculoskeletal structures as shown in the Fig. 21.1.

2. Painful or painless rheumatic diseases as shown in the Fig. 21.2.

\subsection{Carpal Tunnel Syndrome}

Carpal tunnel syndrome (CTS) is an entrapment neuropathy caused by compression of the median nerve resulting in pain and/or paraesthesia in thumb, index and middle finger.

\subsubsection{Epidemiology}

- In diabetic patients: CTS is common and estimated to occur in $\mathbf{1 4 \%}$ in patients without diabetic polyneuropathies and up to $\mathbf{3 0 \%}$ in those with diabetic polyneuropathies [5].

- It may be more common in those with prediabetes [6].

- More common in women than men [7].

- In nondiabetics with life expectancy of 70 years: $\mathbf{3 - 5 \%}$ in Men and $\mathbf{1 1 \%}$ in women are expected to develop CTS [7].

\subsubsection{Approach to CTS}

\subsubsection{History}

- Numbness and tingling sensation: it should be localized to the palmer aspect of the first to the fourth fingers and the distal palm. These symptoms usually happen at night and resolve by shaking (shake sign).

- Pain: usually at night, and over the ventral aspect of the wrist and radiated distally to the palm and fingers or proximally to the ventral forearm, resolved by flicking (flicking sign).

The musculoskeletal structures involved in diabetes-associated rheumatological diseases

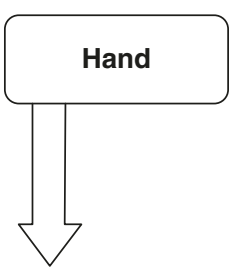

- Carpal tunnel syndrome

- Dupuytren's contracture

- Flexor tenosynovitis (Trigger Finger)

- Diabetic cheiroarthropathy (Stiff-hand syndrome)

- Limited joint mobility

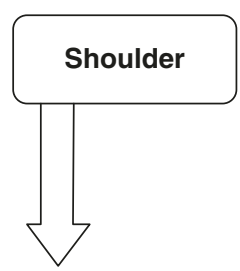

- Limited joint mobility

- Adhesive capsulitis

- Calcific periarthritis

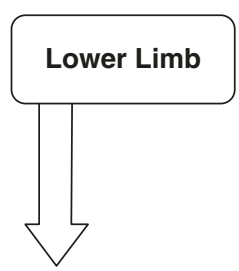

- Neuropathic arthropathy e.g, Charcot joint

- Diabetic muscle infarction (thigh and calf)

- Osteoarthritis (knee)

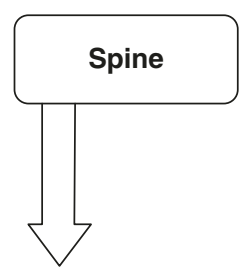

- Diffuse idiopathic skeletal hyperostosis (DISH)

Fig. 21.1 The musculoskeletal structures involved in diabetes-associated rheumatological diseases 


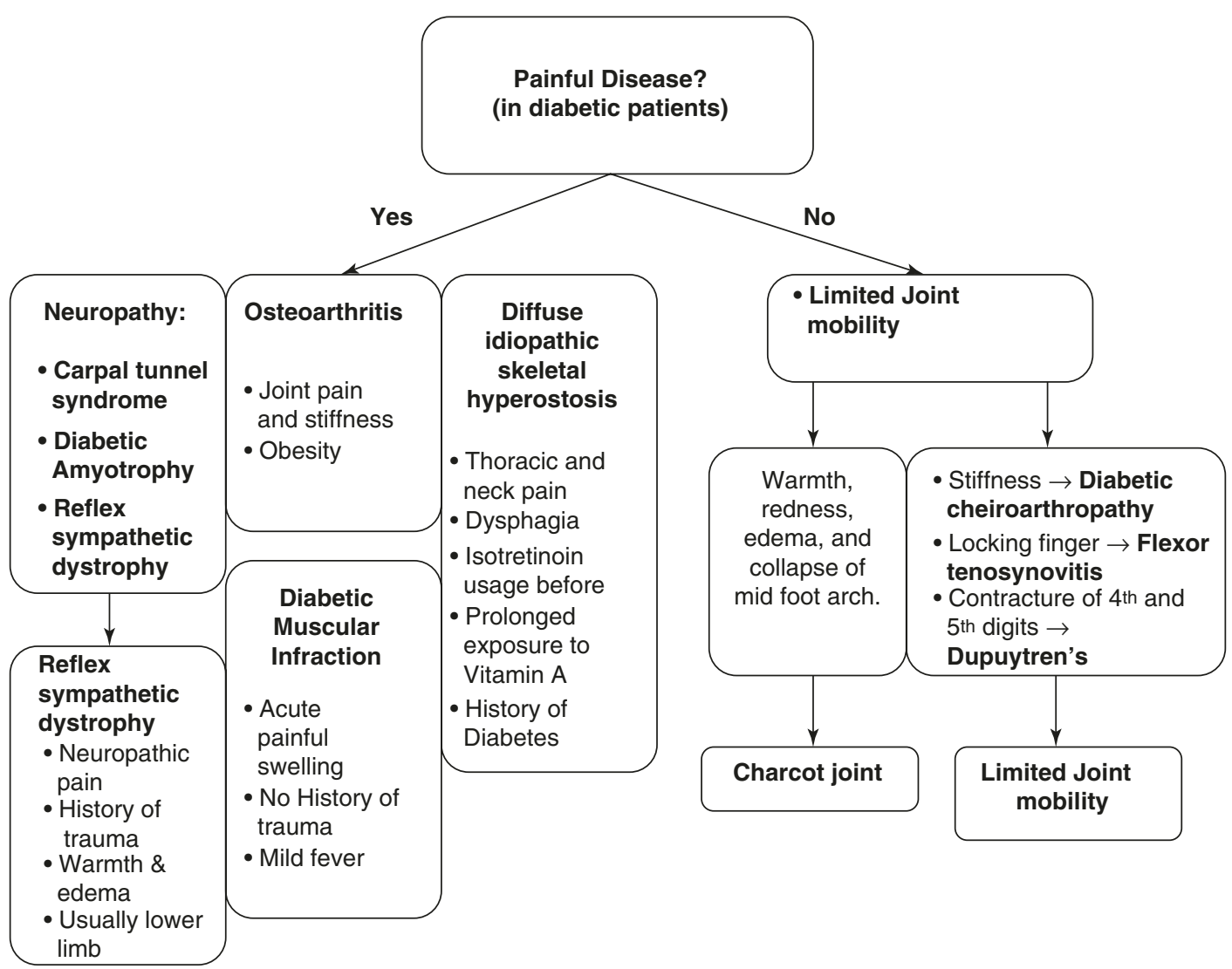

Fig. 21.2 Painful and painless rheumatic diseases associated with diabetes mellitus

- Autonomic symptoms: temperature and colour changes in the hand.

- Weakness of thumb abduction and opposition.

To exclude other causes of CTS, the following should be assessed for establishing the diagnosis (Table 21.1):

\subsubsection{Physical Examination}

- Motor Examination: wasting and weakness of the median-innervated hand muscles (LOAF); first and second lumbricales, opponens pollicis, abductor pollicis brevis and flexor pollicis brevis may be detectable and resulting in weak thumb abduction.

\section{- Sensory Examination:}

- Decreased sensation in the median nerve distribution (from thumb through the middle of the fourth finger).
- Semmes-Weinstein monofilament testing or 2-point discrimination, which may be more sensitive in picking up the sensory abnormality.

\section{- Special tests:}

- Phalen test (87\% specificity and $84 \%$ sensitivity): the patient has to hold his hands against each other in full palmer flexion; paraesthesia will happen within 30 to $120 \mathrm{~s}$ in this position.

- Tinel sign (89\% specificity and $82 \%$ sensitivity): gentle tapping over the median nerve in the carpal tunnel area causes tingling in the nerve's distribution.

- The carpal compression test (sensitivity $84 \%$, specificity $82 \%$ ): applying firm pressure directly over the carpal tunnel, usually with the thumbs, for up to $30 \mathrm{~s}$ will reproduce the symptoms. 
Table 21.1 Causes of Carpal Tunnel Syndrome

\begin{tabular}{|c|l|}
\hline Causes & \multicolumn{1}{c|}{ Important Differentiating Tips } \\
\hline Diabetes & $\begin{array}{l}\text { Numbness, neuropathy, retinopathy, nephropathy, and peripheral vascular } \\
\text { disease }\end{array}$ \\
\hline $\begin{array}{c}\text { Rheumatoid } \\
\text { Arthritis }\end{array}$ & Constitutional symptoms, polyarthritis, morning stiffness, positive RF and ACPA \\
\hline Gout & $\begin{array}{l}\text { Monoarthritis, hyperuricemia, monosodium urate crystals in synovial fluid, } \\
\text { negative culture of joint fluid for microorganisms }\end{array}$ \\
\hline Heart failure & $\begin{array}{l}\text { Orthopnea, PND, ischemic heart disease, diabetes, } \\
\text { Hypertension }\end{array}$ \\
\hline Hyperthyroidism & Palpitation, heat intolerance, weight loss, goitre, suppressed TSH \\
\hline Colles' fracture & History of trauma \\
\hline Over use syndrome & Work related e.g. computer Users, typists, and musicians \\
\hline
\end{tabular}

Abbreviations: RF: Rheumatiod factor, ACPA: Anti-citrullinated protein antibodies, PND: Paroxysmal nocturnal dyspnea, TSH: Thyroid stimulating hormone

- Hand elevation test (89\% specificity and $87 \%$ sensitivity): asking the patient to raise the affected hand and holding it in that position for $1 \mathrm{~min}$. The test is positive when tingling and numbness happen in the median nerve distribution area.

\subsubsection{Investigations}

- Carpal tunnel syndrome is a clinical diagnosis.

- Lab tests are usually not helpful except for assessing glycaemic control.

- Nerve conduction studies (NCS) and electromyography (EMG): are the diagnostic tests that usually used to confirm the diagnosis, assess severity and rule out other abnormalities or conditions such as polyneuropathy, plexopathy and radiculopathy.

- Imaging studies are not routinely used:

- Ultrasound (sensitivity 64\%):

It can demonstrate the thickening of the median nerve, the flattening of the nerve within the tunnel and the bowing of the flexor retinaculum, which are all features that indicate the presence of CTS.
- MRI (sensitivity 96\%):

It demonstrates swelling of the median nerve and increased signal intensity on T2-weighted images, indicating accumulation of the axonal transportation, myelin sheath degeneration or oedema, which are suggestive of CTS.

\subsubsection{Treatment}

- Conservative treatment:

- Splinting: splinting the wrist at night-time for a minimum of 3 weeks. Many off-theshelf wrist splints seem to help.

- Steroid injection, nonsteroid antiinflammatory drug and vitamin B6: effective in reducing inflammation and oedema $[8,9]$.

- Surgical release of carpal tunnel:

- This is performed more frequently among patients with $D M$ and is estimated to be 4-14 times higher than the general population.

- Success rate is more than $90 \%$. 


\subsection{Reflex Sympathetic Dystrophy}

Reflex sympathetic dystrophy (RSD), also known as complex regional pain syndrome I (CRPS I), is characterized by localized or diffuse neuropathic pain of the upper or lower extremity usually associated with swelling, vasomotor disturbances and trophic skin changes which include loss of hair, skin colour changes, temperature changes and skin thickening (autonomic involvement) [10].

\subsubsection{Pathogenesis}

The pathogenesis of RSD is unclear, but there are some theories that may explain it:

- Sympathetic nervous system dysfunction.

- Neurogenic inflammation.

- Central nervous system sensitization.

- Autoimmune condition.

- Limb ischaemia or ischaemia reperfusion injury.

\subsubsection{Epidemiology}

Incidence of RSD is 26.2 per 100,000person year in Netherlands 1996-2005, the highest incidence in women aged $61-70$ years, with a female to male ratio 3.4:1 [11].

\subsubsection{Approach to RSD}

\subsubsection{History}

- Neuropathic pain following an injury (tissue trauma or bony fracture). It is described as burning, throbbing, aching, squeezing or shooting pain.

- Vasomotor and sudomotor changes in the affected limb (colour changes, temperature changes and excessive sweating).

- Ask about the possible precipitating factors or causes such as:

- Trauma kor immobilization following trauma to limb.
- Bone fractures of extremities.

- Diabetes mellitus.

- Hyperthyroidism.

- Hyperparathyroidism.

- Nerve injury.

- Medications, e.g. ACE inhibitors.

\subsubsection{Physical Examination}

- Skin: may be shiny, swollen, thinned, erythematous or cyanotic, with scaling. Temperature may be increased or decreased.

\section{- Extremities:}

- Joint may be stiff with decreased range of motion.

- Signs of chronic lymphoedema.

- Neurologically:

- Sensory changes and weakness may be present.

- Tremor or dystonia in the affected limb.

\subsubsection{Diagnosis Criteria (Table. 21.2)}

\subsubsection{Treatment}

There are different medical and surgical treatment modalities, but they have no strong evidence to support their use.

- The best treatment of RSD is prevention by early mobilization following an injury or stroke and use of supplemental vitamin $\mathrm{C}$ for patients with wrist fractures $[14,15]$. A typical dose is $500-1500 \mathrm{mg}$ daily, and the duration is 50 days.

- Physical therapy.

- Medical therapy:

- Analgesics, e.g., topical capsaicin cream.

- Bisphosphonates.

- Anticonvulsants, e.g., gabapentin.

- Tricyclic antidepressant.

- Vasodilator medication or percutaneous sympathetic blockades.

- Glucocorticoids.

- Invasive therapy for non-improving on noninvasive therapy.

- Regional sympathetic nerve block.

- Electrical nerve stimulation. 
Table 21.2 Diagnostic criteria of reflex sympathetic dystrophy, also known as complex regional pain syndrome

\section{Bruehl's criteria[12]}

Continuing pain disproportionate to any inciting event.

1. Patient must report at least $\mathbf{1}$ symptom in each of the $\mathbf{4}$ following categories

a) Sensory: hyperesthesia

b) Vasomotor: temperature asymmetry, skin color changes or skin color asymmetry

c) Sudomotor/edema: edema, sweating changes or sweating asymmetry

d) Motor/trophic: decreased range of motion, motor dysfunction (weakness, tremor, dystonia) or trophic changes (hair, nail, skin)

2. Must display at least $\mathbf{1}$ sign in $\mathbf{2}$ or more of the following categories

e) Sensory: evidence of hyperalgesia (to pinprick) or allodynia (to light touch)

f) Vasomotor: evidence of temperature asymmetry, skin color changes or asymmetry

g) Sudomotor/edema: evidence of edema, sweating changes or sweating asymmetry

h) Motor/trophic: evidence of decreased range of motion, motor dysfunction

(weakness, tremor, dystonia) or trophic changes (hair, nail, skin)

\section{Veldman's criteria[13]}

1. Presence of $\mathbf{4}$ out of $\mathbf{5}$ symptoms:

a) Diffuse pain during exercise

b) Temperature differences between affected and unaffected extremity

c) Color differences between affected and unaffected extremity

d) Volume differences between affected and unaffected extremity

e) Limitations in active range of movement of the affected extremity

2. Occurrence or increase of symptoms during or after use

3. Symptoms in an area larger than the area of the primary injury

- Sympathectomy.

- Spinal cord stimulation.

\subsection{Flexor Tenosynovitis}

Flexor tenosynovitis, also known as trigger finger, is a non-infectious inflammation of the flexor tendon sheath of the finger leading to finger blocking in flexion with failure of active extension.

\subsubsection{Pathogenesis}

Inflammation causes thickening of flexor tendon of the digit over metacarpal head and resistance to its entrance into the base of flexor tendon sheath, accompanied by constriction of the sheath. Flexors are stronger than extensors, so finger gets locked in a flexed position, as extensors cannot overcome the resistance of constriction.

\subsubsection{Epidemiology}

The prevalence of flexor tenosynovitis is estimated at $11 \%$ in diabetic patients, compared with less than $1 \%$ in nondiabetics [16]. The occurrence of flexor tenosynovitis correlates significantly with the duration of DM, but not with glycaemic control [16]. 


\subsubsection{Approach to Flexor Tenosynovitis}

\subsubsection{History}

- Locking of finger in a flexed position with a resistance to re-extension. It commonly involves thumb, the middle and ring fingers.

- Clicking of the locked digit and finger pain.

\subsubsection{Physical Examination}

- Local tenderness and palpable swelling at the base of the finger, where the tendon crosses over the metacarpal head.

- Pain usually gets worse by stretching the tendon in extension or by resisting flexion isometrically.

- Prayer sign test: the ability to flatten the hands together as in prayer, facilitating recognition of contractures in the metacarpophalangeal, proximal interphalangeal and distal interphalangeal joints.

- Table top test: assesses the ability to flatten the palm against the surface of a table, facilitating recognition of contractures in the metacarpophalangeal joints.

\subsubsection{Investigations}

- It is a clinical diagnosis.

- Plain radiographs are rarely done unless there is a history of trauma or inflammatory diseases. They may show calcification of the tendon but rarely occurs.

\subsubsection{Treatment [17]}

- Activity modifications to avoid the triggers.

- Splinting.

- NSAIDs.

- Steroid injections into tendon sheath.

- Surgical release.

\subsection{Diabetic Muscular Infarction}

It refers to spontaneous ischemic necrosis of skeletal muscles, unrelated to athero-embolism or occlusion of major arteries. Diabetic muscle infarction (DMI) is a rare but life threatening complication seen in patients with long-standing and poorly controlled diabetes. It is considered as one of the micro- and macrovascular complications of Diabetes.

\subsubsection{Pathophysiology}

DMI is more common in type I diabetes and most of the affected patients have multiple microvascular complications. Hyperglycaemia, with or without insulin resistance, has many potentially adverse effects on the arterial vasculature. It may also affect platelets functions and the levels of coagulation and thrombolytic factors leading to occlusion of arterioles and capillaries resulting in muscles necrosis and oedema.

\subsubsection{Epidemiology}

- More common with type I diabetes.

- Usually affecting women more than men.

- Usually associated with other complications of diabetes as nephropathy (70\%), retinopathy $(57 \%)$ and neuropathy $(55 \%)$ [18]

\subsubsection{Approach to DMI}

\subsubsection{History}

- Tender and swollen leg.

- Pain of an acute onset in the thigh and less commonly in the calf muscles over days.

- Autonomic symptoms: mild fever.

- Ask about trauma: usually there is no history of trauma in DMI.

- Ask about suspected complications as recurrence or staph sepsis.

- Ask about the diabetes control and medication use.

- Ask about symptoms of nephropathy and retinopathy, e.g. urinary symptoms and vision problems. 


\subsubsection{Physical Examination}

- Assessing the leg swelling: site, size, shape, tenderness and temperature.

- Any associated leg ulcers?

- Check the leg and upper limb arterial pulses.

- Look for signs of DM-related micro- and macrovascular complications such as retinopathy, neuropathy and cardiovascular abnormalities.

\subsubsection{Imaging Studies}

\section{- MRI:}

- Shows a high intensity in the involved muscle as well as subcutaneous oedema and subfascial fluid (in T2-weighted sequences), in addition to loss of the normal fatty intramuscular septa with T1-weighted images (common finding) [19].

- It is the diagnostic test of choice.

- Ultrasonography:

- Finding of internal linear echogenic structures, absence of a predominant anechoic area and no evidence of internal motion can discriminate a diabetic muscle infarction from an abscess.

- Venous Doppler ultrasound with compression to rule out venous thrombosis.

- Arteriography:

- It may show atherosclerotic luminal narrowing. Generally, it is not used for diagnosis.

\subsubsection{Muscle Biopsy (for Confirmation)}

The primary pathological findings are muscle necrosis and oedema, but occlusion of arterioles and capillaries by fibrin may also be seen. It should be reserved for patients with atypical presentation, uncertain diagnosis or those who do not improve with medical treatment [20].

\subsubsection{Treatment}

- Rest and analgesics.

- Anti-platelet agents (ASA) and/or antiinflammatory drugs.

- Surgical excision.

\subsection{Adhesive Capsulitis (Frozen Shoulder)}

Adhesive capsulitis, also known as frozen shoulder, is characterized by progressive painful restriction of the shoulder movements, especially external rotation and abduction. Typically, the pain of frozen shoulder in diabetics is less than that of nondiabetic patients.

\subsubsection{Pathogenesis}

The exact mechanism is unknown. It is thought that hyperglycaemia can lead to a faster rate of collagen glycosylation and cross-linking in the shoulder capsule, which will cause thickening and contraction of the capsule that result in a substantial decrease in capsular volume capacity.

\subsubsection{Epidemiology}

- The prevalence of frozen shoulder is estimated to be 2 to $5 \%$ of the general population [21, 22].

- Patients with diabetes mellitus are at a greater risk of developing frozen shoulder, with prevalence of 10 to $20 \%$ [23-25].

- Bilateral involvement is more frequent in diabetic patients than in nondiabetic subjects (33 to $42 \%$ vs. 5 to $20 \%$ ) [26].

- Women are more often affected than men [27].

\subsubsection{Approach to Frozen Shoulder}

\subsubsection{History}

- Shoulder stiffness.

- Diffuse severe pain, even at night.

- Limitation of shoulder motion.

- The followings should be obtained:

- Duration and location of pain.

- Precipitating and relieving factors.

- One shoulder or both are affected.

- Any other joints involved.

- Any strain, overuse or trauma. 
Table 21.3 Frozen shoulder progression phases [22, 28]

\begin{tabular}{|c|c|c|}
\hline Painful freezing phase & Adhesive phase & Resolution phase \\
\hline $\begin{array}{l}\text { - } \quad \text { Pain and stiffness around } \\
\text { the shoulder with no } \\
\text { history of injury } \\
\text { - Constant pain with little } \\
\text { response to NSAIDs }\end{array}$ & 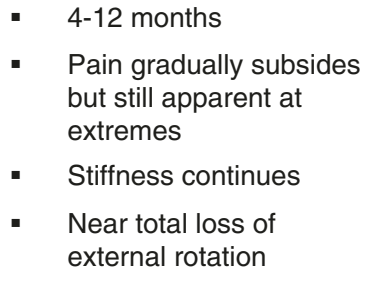 & $\begin{array}{l}\text { - } \quad \begin{array}{l}\text { Spontaneous } \\
\text { improvement in the } \\
\text { range of motion }\end{array} \\
\text { - Mean duration of } \\
\text { overall impairment } \\
>30 \text { months }\end{array}$ \\
\hline
\end{tabular}

- Prolonged immobilization.

- Neck pain or radiation of pain into arms.

- Neurologic symptoms in arms.

Frozen Shoulder May Progress Through Three Theoretical Phases [22, 28] (Table. 21.3).

\subsubsection{Physical Examination}

A stiff and painful glenohumeral joint makes it difficult to perform a complete shoulder examination.

- Look for swelling, redness and warmth.

- Check distal strength, sensation and pulses.

- Check for diffuse tenderness over anterior and posterior aspect of the shoulder.

- Lock for loss of active and passive motion in all planes especially on external rotation and abduction.

- Diagnosis is unlikely if complete abduction present on passive motion.

\subsubsection{Imaging}

- Plain radiographs are usually normal, so had limited diagnostic use.

- Ultrasonography is used either to confirm the diagnosis of frozen shoulder or to rule out other pathology of the rotator cuff and bursa. Findings associated with frozen shoulder may include [29]:

- Thickening of the coracohumeral ligament and the soft-tissue structures in the rotator cuff interval.
- Increased fluid in the tendon sheath of the long head of the biceps.

- Increased vascularity around the intraarticular portion of the biceps tendon and the coracohumeral ligament.

- MRI shows a thickening of the joint capsule and the coracohumeral ligament. It is useful in some conditions like rotator cuff tendinopathy and concomitant glenohumeral osteoarthritis for accurate diagnosis.

\subsubsection{Treatment}

In most cases, frozen shoulder is a self-limited condition, although a complete resolution does not occur in many patients.

- Physical therapy.

- Nonsteroidal anti-inflammatory drugs (NSAIDs) and analgesics.

- Intra-articular steroid injections.

- Surgery in severe non-responding cases.

\subsection{Neuropathic Osteoarthropathy (Charcot Joint)}

Neuropathic osteoarthropathy, also known as Charcot osteoarthropathy, is a progressive destructive process affecting the bone and joint structures associated with various diseases in 
which neuropathy occurs. However, DM is by far the most common aetiology.

\subsubsection{Pathogenesis}

The pathogenesis remains uncertain, but it is probably due to an underlying diabetic peripheral neuropathy and a combination of mechanical trauma and vascular factors. It may result from repeated trauma, often minor, in the setting of decreased sensation due to a sensory neuropathy, which results in increased damage with microfractures (Fig. 21.3).

\subsubsection{Epidemiology}

- Among the general diabetic population, neuroarthropathy is uncommon, affecting approximately 1 in 700 diabetic patients $[30,31]$.

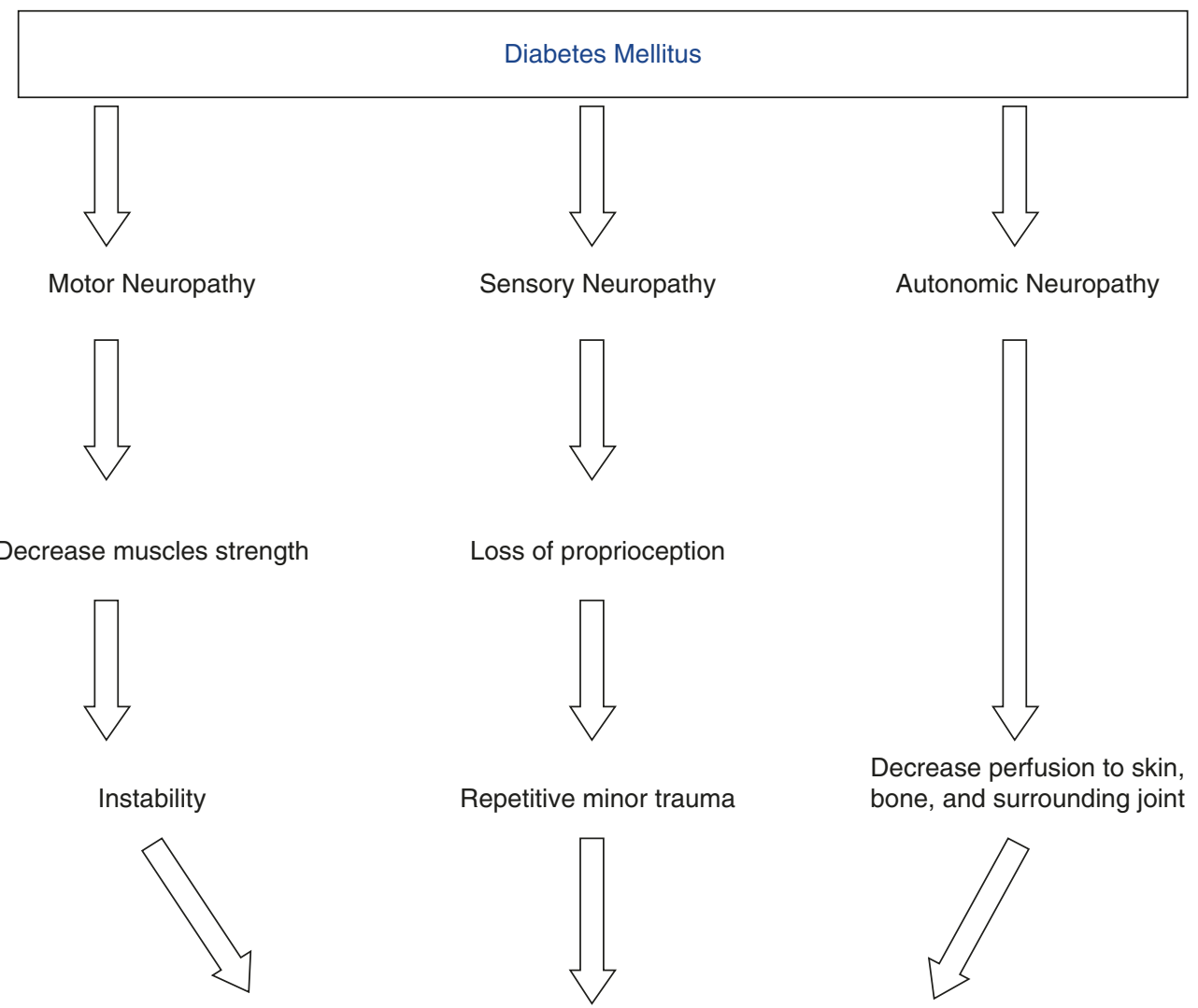

DIABETIC NEUROPATHIC ARTHROPATHY

Ulceration and infection

Fig. 21.3 Pathogenesis of diabetic neuropathic arthropathy 
Table. 21.4 The Modified Eichenholtz System to Stage Charcot Joint Progression

\begin{tabular}{|c|c|c|c|}
\hline $\begin{array}{c}\text { Inflammatory } \\
(\text { Stage 0) }\end{array}$ & $\begin{array}{l}\text { Development } \\
\text { (Stage 1) }\end{array}$ & $\begin{array}{c}\text { Coalescence } \\
\text { (Stage 2) }\end{array}$ & $\begin{array}{c}\text { Remodeling } \\
\text { (Stage 3) }\end{array}$ \\
\hline $\begin{array}{l}\text { - Localized swelling, } \\
\text { erythema, and } \\
\text { warmth } \\
\text { - No radiological } \\
\text { abnormalities }\end{array}$ & $\begin{array}{l}\text { - Persistent } \\
\text { swelling, redness, and } \\
\text { warmth } \\
\text { - Bony changes } \\
\text { such as fracture, } \\
\text { subluxation, } \\
\text { dislocation } \\
\text { - Bony debris } \\
\text { starts to appear } \\
\text { radiologically }\end{array}$ & $\begin{array}{l}\text { - Inflammatory } \\
\text { signs decrease } \\
\text { - Radiological } \\
\text { signs of } \\
\text { fracture } \\
\text { healing, bony } \\
\text { debris } \\
\text { resorption } \\
\text { - New bone } \\
\text { formation }\end{array}$ & $\begin{array}{l}\text { Clinical } \\
\text { inflammatory } \\
\text { signs have } \\
\text { settled } \\
\text { - Bony deformity } \\
\text { - Radiologically, } \\
\text { may show } \\
\text { mature fracture } \\
\text { and decreased } \\
\text { sclerosis }\end{array}$ \\
\hline
\end{tabular}

- Patients at risk are usually those who have longstanding diabetes (average duration 15 years) with peripheral neuropathy and are in their sixth or seventh decade [30, 31].

\subsubsection{Approach to Charcot Joint}

\subsubsection{History}

- Arthritis and swollen foot or ankle (although may occur in any joint).

- The modified Eichenholtz system was developed to stage the progression of Charcot joint and to recommend treatment based on the clinical stage and radiographic changes [32] (Table. 21.4).

\subsubsection{Physical Examination}

- Serial X-rays with different findings according to the stage.

- Inflammatory stage: no radiological abnormalities.

- Development stage: joint effusion, subluxation, bone destruction and osteochondral fragmentation.

- Coalescence stage: periosteal new bone formation, subchondral sclerosis, resorption of debris, marginal osteophytes.

- Remodelling stage: ankylosis or rounded bone ends, decreased sclerosis, decreased swelling.

- MRI: may show bone marrow oedema, bone bruising or microfractures.

\subsubsection{Treatment}

- Avoidance of weight bearing is the mainstay of treatment. It should be for at least 3 months or until erythema and oedema resolve accompanied by radiographic improvements.

- NSAIDs.

- Calcitonin and bisphosphonates may be added on to limb offloading. Their use has not been approved yet in the treatment of Charcot neuroarthropathy $[35,36]$.

- Surgical treatment may only be required when the conservative treatment fails or severe deformities developed.

(Table 21.5) Summary of the Most Common Rheumatological Diseases/Complications in Diabetic Patients.

\subsection{Diabetes and Osteoporosis}

Both diabetes and osteoporosis are prevalent diseases with significantly associated mortalities and morbidities. It has been well established that diabetic patients are at increased risk of osteoporosis and fractures, particularly at the hip.

Osteoporosis is defined as a combination of reduced bone mass and altered bone quality, with microarchitectural abnormalities, resulting in decreased bone strength with an increased risk of fractures [37, 38]. At present, the diagnosis of osteoporosis rests on bone mineral density 
(BMD) measurement using dual-energy X-ray absorptiometry (DXA). The results are reported as the difference, in standard deviations (SDs), with the peak bone mass (-score). The World Health Organization (WHO) defines osteoporosis as a BMD -score of -2.5 or less [37-39].

Table 21.5 Summary of the Most Common Rheumatological Diseases/Complications in Diabetic Patients

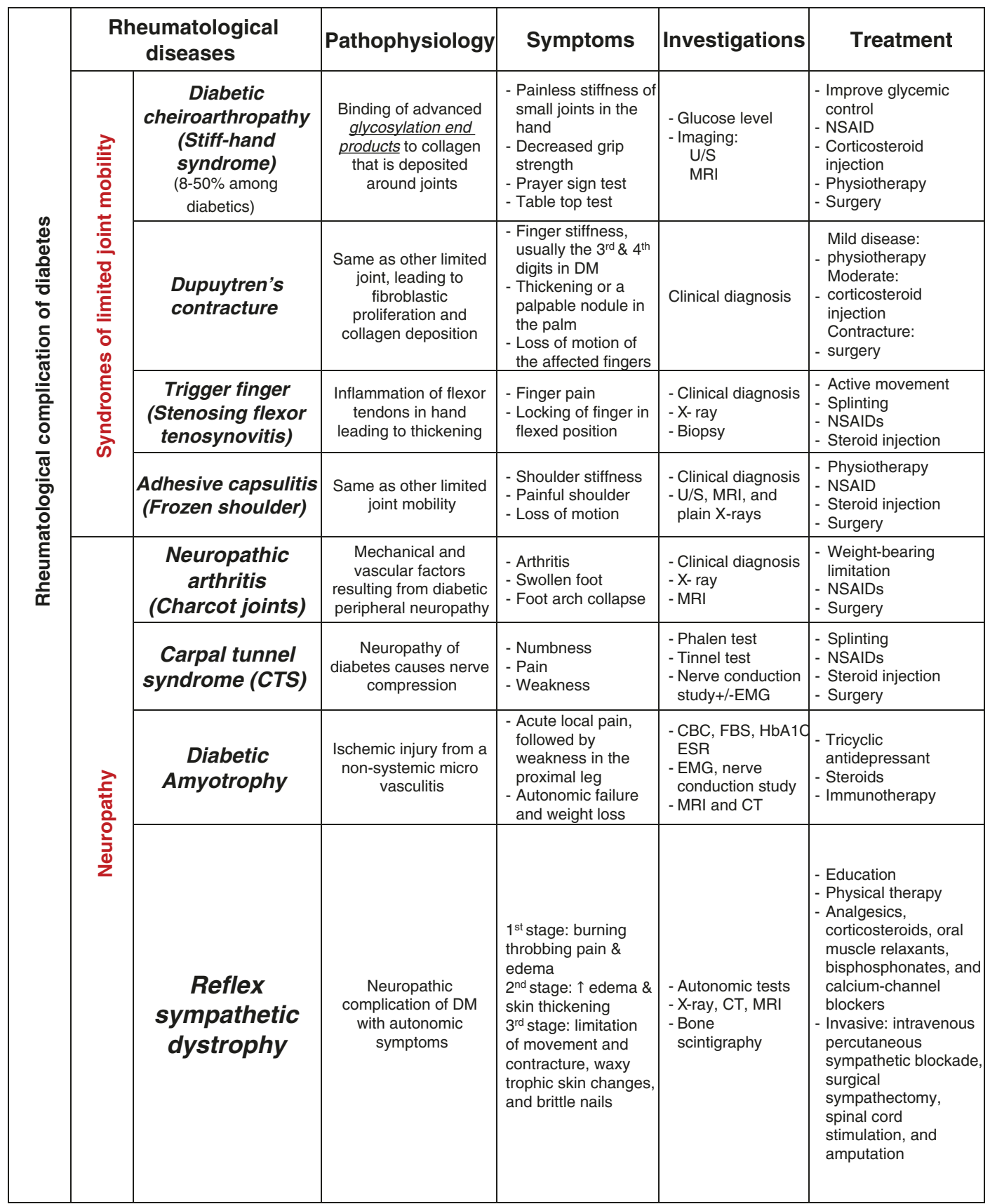


Table 21.5 (continued)

\begin{tabular}{|c|c|c|c|c|c|}
\hline \multirow[b]{2}{*}{ 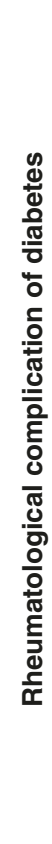 } & $\begin{array}{c}\text { Rheumatologic } \\
\text { al diseases }\end{array}$ & Pathophysiology & Symptoms & Investigations & Treatment \\
\hline & 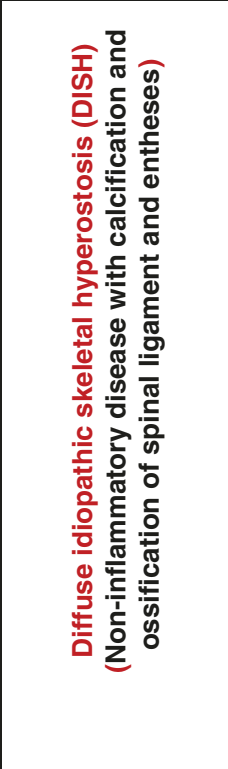 & $\begin{array}{l}\text { - Etiology: unknown, } \\
\text { could be due to } \\
\text { abnormal osteoblastic } \\
\text { activity at the enthesis. } \\
\text { - Insulin-like growth } \\
\text { factor-1, insulin, } \\
\text { glucose, and growth } \\
\text { hormone are involved } \\
\text { in the pathogenesis of } \\
\text { osteoblastic activity in } \\
\text { DISH. } \\
\text { - Other factors : } \\
\text { prolonged exposure to } \\
\text { Vitamin A and fluoride. } \\
\text { - usage of Isotretinoin. } \\
\text { = Mechanical: } \\
\text { Dextrocardia }\end{array}$ & $\begin{array}{l}\text { - Neck, thoracic } \\
\text { spine, low back, } \\
\text { or extremities } \\
\text { pain } \\
\text { - Disability and } \\
\text { spinal morning } \\
\text { stiffness } \\
\text { - May be associated } \\
\text { with dysphagia, } \\
\text { stridor, apnea, } \\
\text { hoarseness, or } \\
\text { thoracic outlet } \\
\text { syndrome due to } \\
\text { large anterior } \\
\text { cervical } \\
\text { osteophytes } \\
\text { - O/E: } \downarrow \text { range of } \\
\text { spinal motion } \\
\text { with tender } \\
\text { entheses }\end{array}$ & $\begin{array}{l}\text { - } \text { Radiologically: } \\
\text { - Thain X-ray: } \\
\text { longitudinal } \\
\text { calcification } \\
\text { and } \\
\text { ossification } \\
\text { - Cervical: } \\
\text { Hyperostosis } \\
\text { with } \\
\text { downward } \\
\text { pointing spurs } \\
\text { Lumbar: } \\
\text { Hyperostosis } \\
\text { with upward } \\
\text { pointing spurs } \\
\text { - CT: is more } \\
\text { sensitive in } \\
\text { detecting } \\
\text { posterior } \\
\text { calcifications }\end{array}$ & $\begin{array}{l}\text { Symptomatic } \\
\text { relief: } \\
\text { - Physical } \\
\text { therapy } \\
\text { - Analgesia: } \\
\text { NSAIDs or } \\
\text { local steroid } \\
\text { - Surgery: } \\
\text { If dysphagia, } \\
\text { myopathy, or } \\
\text { thoracic } \\
\text { outlet } \\
\text { syndrome } \\
\text { developed }\end{array}$ \\
\hline & \multicolumn{5}{|c|}{$\begin{array}{l}\text { Criteria for diagnosis of DISH: } \\
\text { - Resnick and Niwayama Criteria:[31] } \\
\text { 1. Presence of longitudinal ossification and calcification on the anterior surface of at least, } 4 \text { consecutive } \\
\text { vertebral bodies. } \\
\text { 2. Absence of degenerative radiological changes in discs involved with preservation of intervertebral space. } \\
\text { 3. Absence of apophyseal joint bony ankylosis and sacroiliac joint erosion or sclerosis. } \\
\text { - Utsinger Criteria:[32] } \\
\text { 1. Ossification, fine and ribbon-like wave, along the anterolateral aspect of at least } 4 \text { consecutive vertebrae. } \\
\text { 2. Ossification on the anterolateral aspect of at least } 2 \text { consecutive vertebral bodies. } \\
\text { 3. Presence of peripheral and symmetrical entheses pathology, involving heel, patella and olecranon, with } \\
\text { new bone formation. } \\
\text { 1 = definite, } 2 \text { or } 3=\text { probably. }\end{array}$} \\
\hline
\end{tabular}

$A S A$, asprin, $C B C$, complete blood count; $C K$, creatinine kinase; $C T$, computed tomography; $E M G$, electromyography; $E S R$, erythrocyte sedimentation rate; FBG, fasting blood glucose; MRI, magnetic resonance imaging; NSAIDs, non-steroidal anti-inflammatory drugs; $O / E$, on examination; U/S, ultrasound 


\subsubsection{Pathogenesis}

Type I diabetes is associated with bone fragility and loss of bone mass, while type II diabetes, despite having a normal or an increased bone mineral density (BMD), is associated with bone quality deterioration that cannot be diagnosed by using dual-energy X-ray absorptiometry (DXA).

\section{Box 21.1 Risk Factors for Fractures in} Diabetic Patients $[37,40]$

1. Type of diabetes I or II, poor glycaemic control, and risk of drug-induced hypoglycaemia.

2. Microvascular complications of diabetes, especially nephropathy and neuropathy.

3. Type I diabetes-associated diseases such as autoimmune hyperthyroidism, amenorrhea, eating disorders and celiac disease.

4. Increased risk of falls due to diabetesrelated complications such as hypoglycaemia, poor vision and/or balance, autonomic orthostatic hypotension and arthropathy.

5. Vitamin D deficiency, which is more common in diabetics than general population.

\subsubsection{Challenges in Diagnosing and Treating Diabetes-Related Osteoporosis}

Although the risk has been well established, it remains underappreciated in the major international diabetes guidelines and by most clinicians caring for diabetic patients. There have been also insufficient studies evaluating the effectiveness and long-term safety of the available therapeutic antiporotic modalities to reduce the risk of fracture in patients with diabetes.

\subsubsection{Approach to Diabetes-Related Osteoporosis}

\subsubsection{History}

- Type of diabetes and glycaemic control (frequency of hyper- and hypoglycaemia).

- Symptoms of diabetes-related microvascular complications.

- Assess any risk for falls.

- Ask about any of the following risk factors that might increase the risk of osteoporotic fractures:

- Previous history of fracture.

- Parental history of hip fracture.

- Smoking.

- Alcoholism.

- Steroid use.

- Hyperthyroidism, celiac disease, hyperparathyroidism, vitamin D deficiency or rheumatoid arthritis.

\subsubsection{Physical Exam}

- Height measurement for any loss of height.

- Body mass index (low BMI $<19 \mathrm{~kg} / \mathrm{m}^{2}$ ).

- Back examination for kyphosis or point tenderness over a vertebra suggesting a compression fracture.

- Signs that may indicate increased fall risk (difficulty with balance or gait, orthostatic hypotension, lower extremity weakness and or neuropathy, poor vision or hearing).

\subsubsection{Diagnosis}

- Use the current osteoporosis guidelines for screening in patients with diabetes through using dual-energy X-ray absorptiometry (DXA) to measure the bone mineral density (BMD), but keep in mind the fracture risk is high in type II diabetes despite having normal or increased bone mineral density (BMD).

- Use the fracture risk assessment (FRAX) algorithm (www.shef.ac.uk/FRAX/), which is a validated tool used to estimate 10-year risks for major osteoporotic and hip fractures even if BMD is not measured [41]. It has been developed by the metabolic bone disease unit at the University of Sheffield. 


\subsubsection{Management} of Osteoporosis on Diabetic Patients

- Maintain a good glycaemic control.

- Minimize hypoglycaemia as possible.

- Screening and prevention of diabetes-related complications.

- Avoid glitazones (TZDs).

- Identify patients with high risk of falls and prevent falls.

- Good supplementation with calcium (600$1200 \mathrm{mg} /$ day) and vitamin D (at least 800$1000 \mathrm{IU} /$ day).

- Use of specific antiporotic medication (bisphosphonates, denosumab or anabolic agent teriparatide) based on the recommendations of good clinical practice and the patients' factors.

Acknowledgement The author would like to thank Moayad Ahmad Kalantan, MD, and Emad Abdulrahman Bahashwan, MD, for their contributions to this chapter in the previous the edition.

\section{References}

1. Vogt B, Schleicher E, Wieland O. $\varepsilon$-Aminolysine-bound glucose in human tissues obtained at autopsy: increase in diabetes mellitus. Diabetes. 1982;31:1123-7.

2. Alikhani M, Alikhani Z, Boyd C, et al. Advanced glycation end products stimulate osteoblast apoptosis via the MAP kinase and cystolic apoptotic pathways. Bone. 2007;40:345-53.

3. Brownlee M, Cerami A, Vlassara H. Advanced glycosylation end products in tissue and the biochemical basis of diabetic complications. N Engl J Med. 1988;318:1315-21.

4. TJ BKE, Dyer DG, et al. Decrease in skin collagen glycation with improved glycemic control in patients with insulin-dependent diabetes mellitus. J C lin Invest. 1991;87:1910-5.

5. Perkins BA, Olaleye D, Bril V. Carpal tunnel syndrome in patients with diabetic polyneuropathy. Diabetes Care. 2002;25(3):565-9.

6. Gulliford MC, Latinovic R, Charlton J, Hughes RA. Increased incidence of carpal tunnel syndrome up to 10 years before diagnosis of diabetes. Diabetes Care. 2006;29:1929.

7. Newport ML. Upper extremity disorders in women. Clin Orthop Rel at Res. 2000 Mar;372:85-94.
8. Stephens MB, Beutler AI, O'Connor FG. Musculoskeletal injections: a review of the evidence. Am Fam Physician. 2008;78(8):971-6.

9. Atroshi I, Flondell M, Hofer M, Ranstam J. Methylprednisolone injections for the carpal tunnel syndrome: a randomized, placebo-controlled trial. Ann Intern Med. 2013;159:309.

10. Wyatt LH, Ferrance RJ. The musculoskeletal effects of diabetes mellitus. J Can Chiropr Assoc. 2006;50(1):43-50.

11. Bruehl S, Chung OY. Pain. 2007;129:1-2):1.

12. Bruehl S, Harden RN, Galer BS, Saltz S, Bertram M, Backonja M, Gayles R, Rudin N, Bhugra MK, StantonHicks M. External validation of 1ASP diagnostic criteria for complex regional pain syndrome and proposed research diagnostic criteria. International Association for the Study of Pain. Pain. 1999;81:147-54.

13. Veldman PHJM, Reynen HM, Arntz IE, Goris RJA. Signs and symptoms of reflex sympathetic dystrophy: prospective study of 829 patients. Lancet. 1993;342:1012-6.

14. Braus DF, Krauss JK, Strobel J. The shoulder-hand syndrome after stroke: a prospective clinical trial. Ann Neurol. 1994;36:728.

15. Zollinger PE, Tuinebreijer WE, Breederveld RS, Kreis RW. Can vitamin C prevent complex regional pain syndrome in patients with wrist fractures? A randomized, controlled, multicenter dose-response study. J Bone Joint Surg Am. 2007;89:1424.

16. Leden I, Schersten B, Svensson B, Svensson M. Locomotor system disorders in diabetes mellitus. Increased prevalence of palmar flexor tenosynovitis. Scand J Rheumatol. 1983;12(3):260-2.

17. Ryzewicz M, Wolf JM. Trigger digits: principle management, and complications. J Hand Surg Am. 2006;31(1):135-46.

18. Trujillo-Santos AJ. Diabetic muscle infarction: an underdiagnosed complication of long-standing diabetes. Diabetes Care. 2003;26:211.

19. Jelinek JS, Murphey MD, Aboulafia AJ, et al. Muscle infarction in patients with diabetes mellitus: MR imaging findings. Radiology. 1999;211:241.

20. Chester CS, Banker BQ. Focal infarction of muscle in diabetics. Diabetes Care. 1986;9:623-30.

21. Morén-Hybbinette I, Moritz U, Scherstén B. The clinical picture of the painful diabetic shoulderDOUBLEHYPHENnatural history, social consequences and analysis of concomitant hand syndrome. Acta Med Scand. 1987;221:73.

22. Reeves B. The natural history of the frozen shoulder syndrome. Scand J Rheumatol. 1975;4:193.

23. Hsu JE, Anakwenze OA, Warrender WJ, Abboud JA. Current review of adhesive capsulitis. J Shoulder Elb Surg. 2011;20(3):502-14.

24. Dang N, Bensasson M, Mery C. Increased association of diabetes mellitus with capsulitis of the shoulder and shoulder-hand syndrome. Scand J Rheumatol. 1977;6:53. 
25. Huang YP, Fann CY, Chiu YH, et al. Association of diabetes mellitus with the risk of developing adhesive capsulitis of the shoulder: a longitudinal populationbased followup study. Arthritis Care Res (Hoboken). 2013;65:1197.

26. Crispin JC, Alcocer-Varela J. Rheumatologic manifestations of diabetes mellitus. Am J Med. 2003;114(9):753-7.

27. Rizk TE, Pinals RS. Frozen shoulder. Semin Arthritis Rheum. 1982;11:440.

28. Grey RG. The natural history of "idiopathic" frozen shoulder. J Bone Joint Surg Am. 1978;60:564.

29. Bianchi S, Martinoli C. Shoulder. In: Bianchi S, Martinoli C, editors. Ultrasound of the musculoskeletal system. Heidelberg: Berlin; 2007. p. 287.

30. Giurini JM, Chrzan JS, Gibbons GW, Habershaw GM. Charcot's disease in diabetic patients. Correct diagnosis can prevent progressive deformity. Postgrad Med. 1991;89:163.

31. Sinha S, Munichoodappa CS, Kozak GP. Neuroarthropathy (Charcot joints) in diabetes mellitus (clinical study of 101 cases). Medicine. (Baltimo51):191.

32. Wukich DK, Sung W. Charcot arthropathy of the foot and ankle: modern concepts and management review. J Diabetes Complicat. 2009;23:409.

33. Resnick D, Niwayama G. Diagnosis of bone and joint disorders, 1988, Philadelphia, 8, 1563-1615.

34. Utsinger PD. Diffuse idiopathic skeletal hyperostosis. Clin Rheum Dis. 1985;11:325-51.
35. Jude EB, Selby PL, Burgess J, et al. Bisphosphonates in the treatment of Charcot neuroarthropathy: a double-blind randomised controlled trial. Diabetologia. 2001;44:2032.

36. Bem R, Jirkovská A, Fejfarová V, et al. Intranasal calcitonin in the treatment of acute Charcot neuroosteoarthropathy: a randomized controlled trial. Diabetes Care. 2006;29:1392.

37. Jackuliak P, Payer J. Osteoporosis, fractures, and diabetes. Int J Endocrinol. 2014;2014:10. doi:10.1155/2014/820615, 2014, 1

38. NIH Consensus Development Panel on Osteoporosis Prevention, Diagnosis and Therapy. Osteoporosis prevention, diagnosis and therapy. J Am Med Assoc. 2001;285(6):785-95.

39. Kanis JA, Devogelaer J-P, Gennari C. Practical guide for the use of bone mineral measurements in the assessment of treatment of osteoporosis: a position paper of the European Foundation for Osteoporosis and Bone Disease. Osteoporos Int. 1996;6(3):256-61.

40. Milczarczyk A, Franek E. Osteoporosis and bone fractures in patients with diabetes mellitus. Diabetologia Doświadczalna i Kliniczna. 2008;8(2):63-7.

41. Kanis JA, Oden A, Johansson H, Borgström F, Ström $\mathrm{O}$, McCloskey E. FRAX and its applications to clinical practice. Bone. 2009;44(5):734-43.

Open Access This chapter is licensed under the terms of the Creative Commons Attribution 4.0 International License (http://creativecommons.org/licenses/by/4.0/), which permits use, sharing, adaptation, distribution and reproduction in any medium or format, as long as you give appropriate credit to the original author(s) and the source, provide a link to the Creative Commons license and indicate if changes were made.

The images or other third party material in this chapter are included in the chapter's Creative Commons license, unless indicated otherwise in a credit line to the material. If material is not included in the chapter's Creative Commons license and your intended use is not permitted by statutory regulation or exceeds the permitted use, you will need to obtain permission directly from the copyright holder. 